Article

\title{
Physico-Chemical Characterization of South African Waste Moulding Sands
}

\author{
Kolela J. Nyembwe ${ }^{\mathrm{a}}$, Mamookho E. Makhatha ${ }^{\mathrm{b}, *}$, and Takalani Madzivhandila \\ University of Johannesburg, Department of Metallurgy, School of Mining, Metallurgy and Chemical \\ Engineering and Metal Casting Technology Station (UJ-MCTS), P.O.BOX 17011, Doornfontein, 2028, \\ South Africa \\ E-mail: adjosnyembwe@gmail.com, bemakhatha@gmail.com (Corresponding author)
}

\begin{abstract}
Dry analysis techniques including X-ray fluorescence (XRF), X-ray diffraction (XRD), Scanning Electron Microscope (SEM-EDS) and Fourier Transform Infra-red (FTIR) have been used to assess the Physico-chemical of waste sand samples, obtained from different local foundry. The casting process involved included Aluminum in shell sand, brass under alky urethane, grey iron in greensand moulding, high chrome using furan sand, steel casting in alkaline phenolic and lastly cast iron from greensand mould.

The study revealed the transformations and changes which have taken place in the waste sand due to the casting process, in terms of chemical composition, mineralogy, morphology and bonding types. The study demonstrated that the waste sand after the casting process was a completely new material, compared to the original virgin sand used for moulding process.
\end{abstract}

Keywords: Waste sand, mineralogical composition, morphology, sand bonding.

ENGINEERING JOURNAL Volume 20 Issue 5

Received 5 January 2016

Accepted 19 May 2016

Published 25 November 2016

Online at http://www.engj.org/

DOI:10.4186/ej.2016.20.5.35 


\section{Introduction}

The casting process mainly involves pouring of molten metal alloy obtained from the melting furnace into a mould. The molten metal is introduced in the mould cavity through the pouring cup (gating system), acting as plumbing network in order to fill the mould cavity [1]. The metal solidifies taking shape and dimension of the mould cavity and possible cores. The cores and moulds are obtained during moulding and core making process, and are usually composed of refractory aggregates materials. A large majority of South African foundries use silica sand as refractory material in moulding purpose. After the knockout of the casting from the mould, a portion of sand is reused. Hundred reused of the sand is impossible because the sand has lost its properties in terms of fineness and refractoriness. Foundry practice is that a portion of the used sand is discarded to be replaced by new sand. Discarded used sand is generally destined for landfill on municipal site. According to the statistic from the South African Institute of Foundrymen (SAIF), South Africa disposes up to 300000 tonnes of moulding waste sand per annum [2-4]. The nature of the waste sand is dominated by the refractory sand used during the moulding process. This refractory sand represents up $75 \%$ of the mould. The rest of the components in the waste include binders, additives and metal. Studies conducted on the characterisation of the waste sand demonstrated that the cast alloy have also determined the nature of the waste, especially for non-ferrous casting such as copper based alloys [5]. Most of previous conducted and documented studies have focused on wet characterisation, obtained after subjecting the sand to well prescribed environmental protocols. In addition to the separate characterisation techniques documented among which: the bulk chemical and mineralogical characters of the waste foundry sand conducted by [5], [6], [7], and [8], few characterisation data on South African waste sand are documented. In addition to that, documents correlating several waste sand characteristic especially for the waste by-product physio-chemical properties when compared to virgin sand, are not well established [9-13].

The aim of this work is to assess the physicochemical characteristics of the South African waste sand and compare the observed characters to virgin sand samples to make a correlation between the used characterisation techniques. The later, included bulk chemistry (XRF), mineralogy (XRD), morphological analysis (SEM) and residual organics (FTIR).

\section{Materials and Methods}

\subsection{Material}

A total of six used sand samples were collected from local South African foundries, located in the Gauteng province. Each foundry also provided the corresponding virgin (new) sand sample used during the moulding process. Sand sampling and homogenization were conducted according to the waste soil sampling protocol as published by the US-PEA [14]. Approximately $0.5 \mathrm{~kg}$ of each sand material was used as the final sample and was dried in an oven for 2 hours at $105^{\circ} \mathrm{C}$.

The foundries to be part of this research study were selected on the basis of the top six highest sand disposal tonnages. The foundries were also chosen to include non-ferrous and ferrous casting operations. The list of foundries related to the casting processes and the disposed monthly sand tonnage is shown in Table 1.

Table 1. List of foundries with the related casting processes.

\begin{tabular}{lccc}
\hline Foundry Sand & Cast Alloy & Disposed tonnage & Sand Binder used \\
\hline $\mathbf{S}_{1}$ & $\mathrm{Al}-\mathrm{Si}$ & Not obtain & Shel Sand \\
$\mathbf{S}_{2}$ & $\mathrm{Cu}-\mathrm{Zn}$ & $15-20$ & Alkyd urethane \\
$\mathbf{S}_{3}$ & $\mathrm{Fe}(\mathrm{SG})$ & 8000 & Greensand \\
$\mathbf{S}_{4}$ & $\mathrm{H}-\mathrm{Cr}$ & 6000 & Furan \\
$\mathbf{S}_{5}$ & $\mathrm{Fe}-\mathrm{C}$ & 7000 & Alkaline Phenolic \\
$\mathbf{S}_{6}$ & $\mathrm{Fe}(\mathrm{SG})$ & 6000 & Greensand \\
\hline
\end{tabular}




\subsection{Method}

The sequence diagram bellow reviews the methodology conducted on the collected foundry sands:

\section{Foundry Sand Samples}

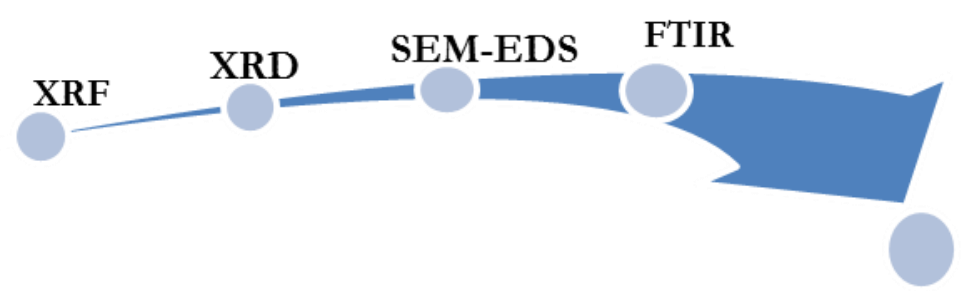

\section{Findings}

Diagram 1. Summary of the conducted methodology.

A four step process shown in the diagram 1 was used to fully analyse the sand samples described above:

a. X-ray fluorescence (XRF) and X-ray diffraction (XRD) techniques were used to determine the bulk chemical composition respectively in terms of elemental chemical and mineralogical composition. An XRF Rigaku ZSX Primus II equipment was used for XRF while an XRD Rigaku Ultima equipment with PDXL analysis software was employed for XRD.

b. Scanning electron microscope equipped with energy dispersed spectrum (SEM-EDS) was used to assess the morphology and to determine the chemical composition on a selected grain surface point in terms of sintering (fusion) and coating. A SEM TESCAN was employed for the grain morphology while the EDS analysis software, determined the chemistry of the desired grain surface point.

c. Fourier Transform Infra-red (FTIR) spectrometer was used to determine residual organic group present in the sand sample. A Thermo Fisher Smart iTR Nicolet equipment was used for this purpose.

\section{Results and Discussion}

\subsection{Chemical Analysis (X-Ray Fluorescence) Results}

Figure 1 bellow composed of chart A to F shows the chemical analysis obtained by XRF for the different waste sand samples with their corresponding new sand used in a particular foundry. The representative waste samples originated from the Aluminium, brass, grey iron, high chrome, and steel and cast iron foundries. The elements of interest in the sand sample were alloying elements present in the cast metal.

All tested sand samples (chart A to F) displayed an increase in concentration of metallic alloying element present in the cast metal in the waste sand, compared to the concentration in the new sand. In all cases, the highest concentration in the waste sand compared to the new sand is related to the principal alloying elements of the cast metal. With exception of light metals (Alkali earth), and silicon, six out of the sixteen heavy stipulated metals were present in the waste sand samples regardless of the cast alloy. These metals included chrome $(\mathrm{Cr})$, copper $(\mathrm{Cu})$, lead $(\mathrm{Pb})$, nickel $(\mathrm{Ni})$, Manganese $(\mathrm{Mn})$ and zinc $(\mathrm{Zn})$.

Aluminium (Al) concentration increased by $3.85 \%$ points in the aluminium casting waste sand (S1). As, depicted in chart A of Fig. 1. This augmentation in metallic content suggests a sand contamination promoted by the cast alloy (Al).

The same could be said in the case of copper $(\mathrm{Cu})$ and Zinc $(\mathrm{Zn})$, which increased distinctively by $0.37 \%$ and $0.11 \%$ point in the used sand obtained from the brass (S2) casting facility (chart B). The observed increases of these metals $(\mathrm{Cu}$ and $\mathrm{Zn})$ could be related to the casting alloy. The latter, being brass. Lastly, the waste sand originating from the brass casting also showed an increase in lead (Pb) by $0.11 \%$ points. In this case, the presence of $\mathrm{Pb}$ is attributed to both: firstly, the binder modification (alkyd urethane) in order 
to fasten the curing time, a certain amount of lead in added [15-16] secondly, the cast alloy. The latter, contains up to $8 \%$ of $\mathrm{Pb}$, enhancing better machinability of brass [17].

The iron $(\mathrm{Fe})$ concentration increased in all ferrous casting waste sand samples and could be related to the dominating main ingredient ( $\mathrm{Fe}$ ), existing within the cast alloy. Its content increased by $5.8 \%$ point, in the waste sand originating from the grey iron (S3) casting sand, shown in chart C. $2.93 \%, 6.77 \%$ and $4.97 \%$ points increase in the Fe content were also observed in the waste sand obtained from: the high chrome (S4) in chart $\mathrm{D}$, steel (S5) from chart $\mathrm{E}$ and cast iron (S6) as present in chart $\mathrm{F}$.

The chrome content also increased by $1.7 \%$ points in the waste sand obtained from the high chrome casting sand (chart D) and by $0.78 \%$ points higher in the steel (S5) casting waste sand, as presented in chart E. The appearance of chrome in these casting sands exposed the sand contamination promoted by the cast alloy, through the alloying element. Since, chrome represents the alloying element for these castings (high chrome and steel). Its content can reach $12 \%$ in steel and up to $30 \%$ in high chrome. In addition to that, waste greensand samples S3 and S6, individually obtained from grey and cast iron casting sand, revealed an increase in their chrome content by $0.19 \%$ in grey iron waste sand. It could be attributed to the bentonite clay, acting as the moulding binder. Since, $\mathrm{Cr}$ is present in the bentonite clay grain matrix [15].

The manganese $(\mathrm{Mn})$ content was also increased in all ferrous casting waste sands, in which the greensand system reported the highest content (chart $\mathrm{C}$ and F). The grey iron casting waste sand (S3) revealed an increase by $0.42 \%$ point as depicted in chart $\mathrm{C}$. Chart $\mathrm{F}$ showed its increase by $0.56 \%$ point in the waste sand originating from the cast iron facility (S6). In both cases, the Mn augmented in waste samples using bentonite as their moulding binder, promoting the sand contamination in regards to $\mathrm{Mn}$ brought in by the binder.

\section{S1 (Aluminum Casting sands)}

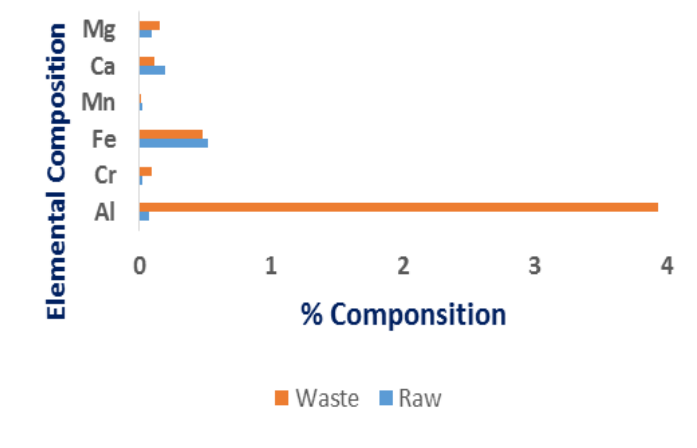

Chart A

\section{S2 (Brass Casting sands)}

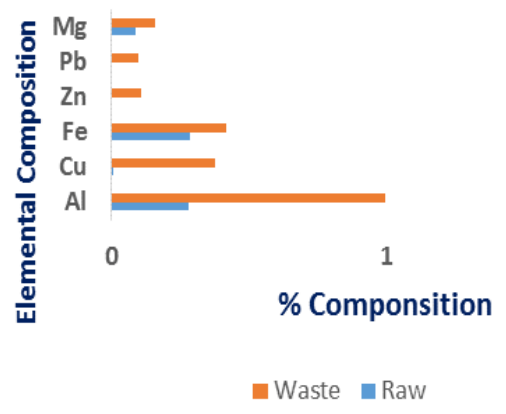

Chart B

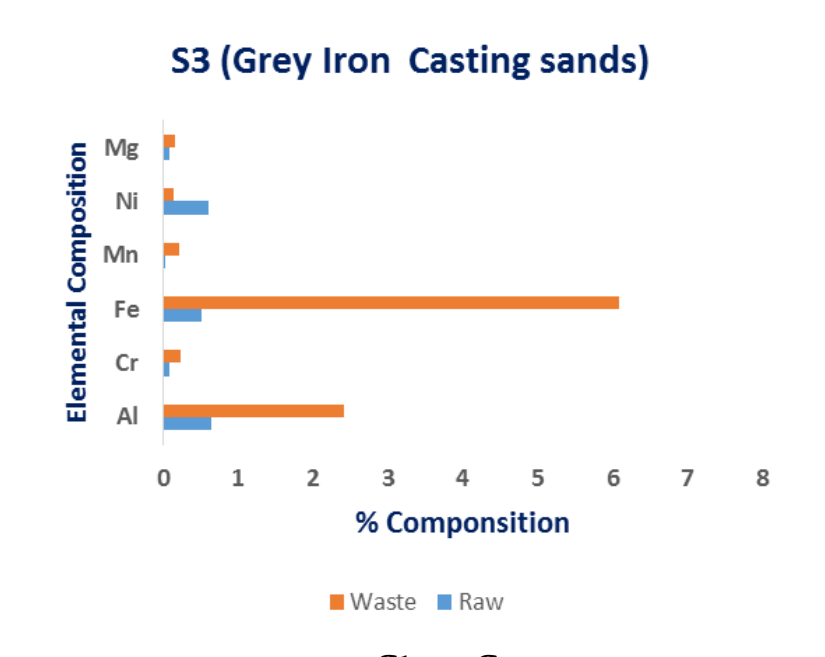

Chart C

\section{S4 (High Chrome Casting sands)}

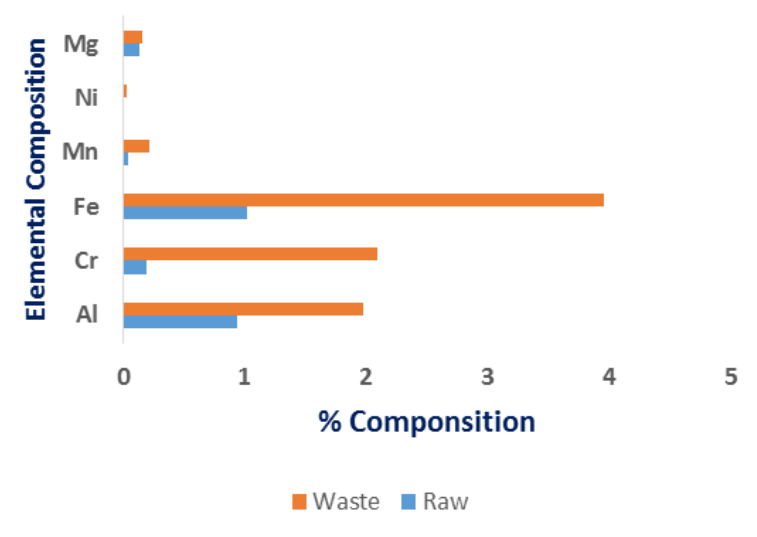

Chart D 


\section{S5 (Steel Casting sands)}

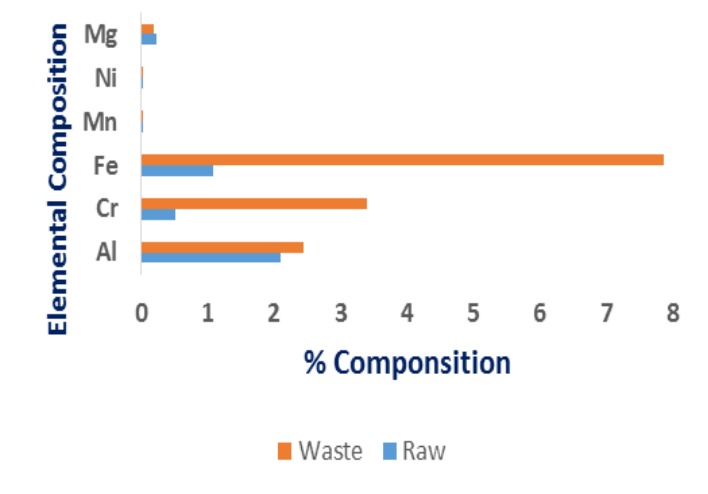

Chart E

\section{S6 (Cast IronCasting sands)}

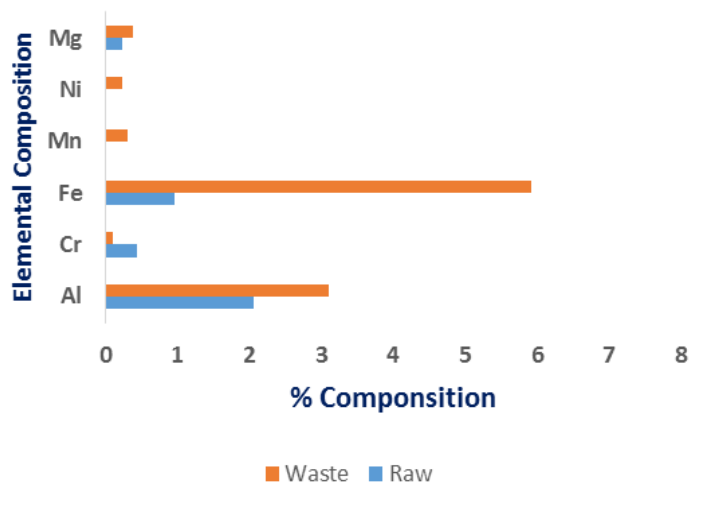

Chart F

Fig. 1. Bulk chemical composition the different foundry sand sample.

\subsection{Mineralogical Characterization (X-Ray Diffraction)}

Diffraction pattern 1 to 6 show the mineralogical composition obtained by XRD for the different waste sand samples with their corresponding new sand, used in the particular casting. The new sand spectra show the silica peak as the main mineral component in the sand. On the other hand, the obtained waste foundry sand spectra revealed the appearance of new peaks, indicating new mineralised phases within the waste samples. These new phases in the waste sands acted as impurities, which reduced the peak intensity of mineralised quartz (silica) as compared to the new sand.

Diffraction pattern 1 shows the presence of anorthite and alumina phases in the waste from the shell sand, casting aluminium. While, the diffraction pattern 2 obtained from the brass waste alkyd urethane sand did not exhibit any new mineralised crystal phase. Diffraction pattern 3 obtained from grey iron using greensand revealed a crystallised phase of Microline. Anorthite was again observed in the high chrome casting waste furan sand from the diffraction pattern 4. Steel waste phenolic sand diffraction pattern 5 exhibits also anorthite and crystalline phase of wustite. Lastly, waste greensand acquired from cast iron casting (diffraction pattern 6) showed wustite and periclase as new mineralised phase within the waste sand.

The appearance of crystallised anorthite $\left.(\mathrm{Na}, \mathrm{Ca}) \mathrm{Al}_{2} \mathrm{Si}_{2} \mathrm{O}_{8}\right)$ in all chemically bonded waste casting sands including shell (diffraction pattern 1), furan (diffraction pattern 4) and alkaline phenolic (diffraction pattern 6), could be attributed to reaction taking place between the sand, binder and metal, promoted by the high casting temperature. Since, these specific waste sands (chemically bonded) revealed a relatively high content of alkali and alkaline earth elements. In regards, to potassium $(\mathrm{K})$ and calcium $(\mathrm{Ca})$.

Feldspar and dolomitic mineral were found as new phase in the waste sands originating from greensand casting systems. Individually, microline $\left(\mathrm{NaAlSiO}_{3} \mathrm{O}_{8}\right)$ was identified in the grey iron casting waste sand on spectra 3 and periclase $(\mathrm{MgO})$ was observed in the cast ion waste casting sand as shown in spectra 6 . These minerals as observed in waste greensand could be associated to the bentonite clay, used as moulding binder. As, sodium $(\mathrm{Na})$ and magnesium $(\mathrm{Mg})$ are constituent of the bentonite grain matrix. In addition to that, their proportions were found higher in greensand as compared to their corresponding virgin sands and chemically bonded waste sand.

Wustite phase $(\mathrm{FeO})$ was detected in all ferrous casting waste sand systems (greensand and chemically bonded sands). These moulding waste sands derived the following cast alloys: high chrome and steel and cast iron. Its presence put forward an oxidation process of iron, contained in the metallic traces from the cast alloy in the waste sand. Since, this phase was only observed in waste casting sands producing ferrous castings (diffraction pattern 3, 4, 5 and 6). 
Diffraction pattern 1: Aluminium casting sand XRD spectrum

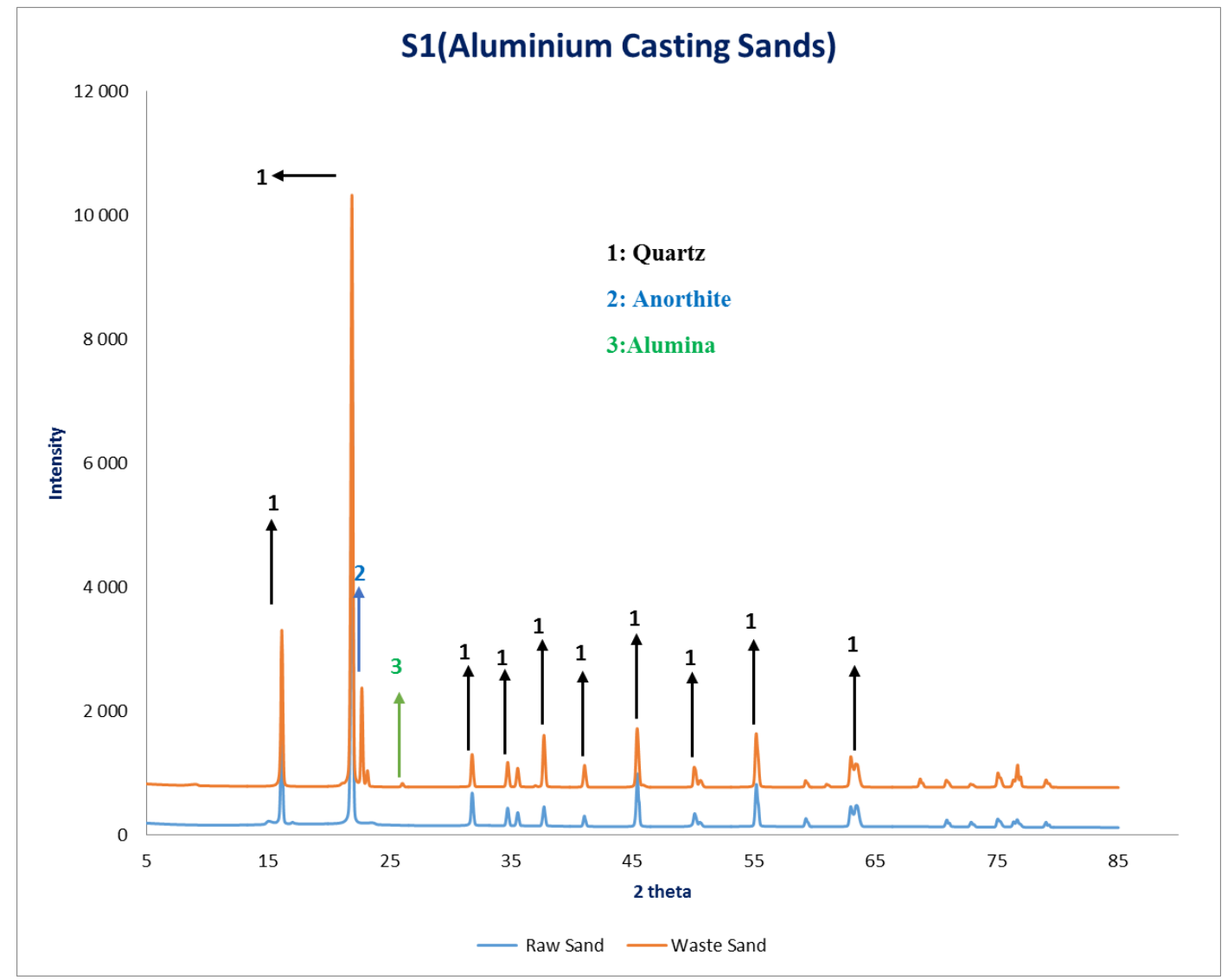

Diffraction pattern 2: Brass casting sand XRD spectrum

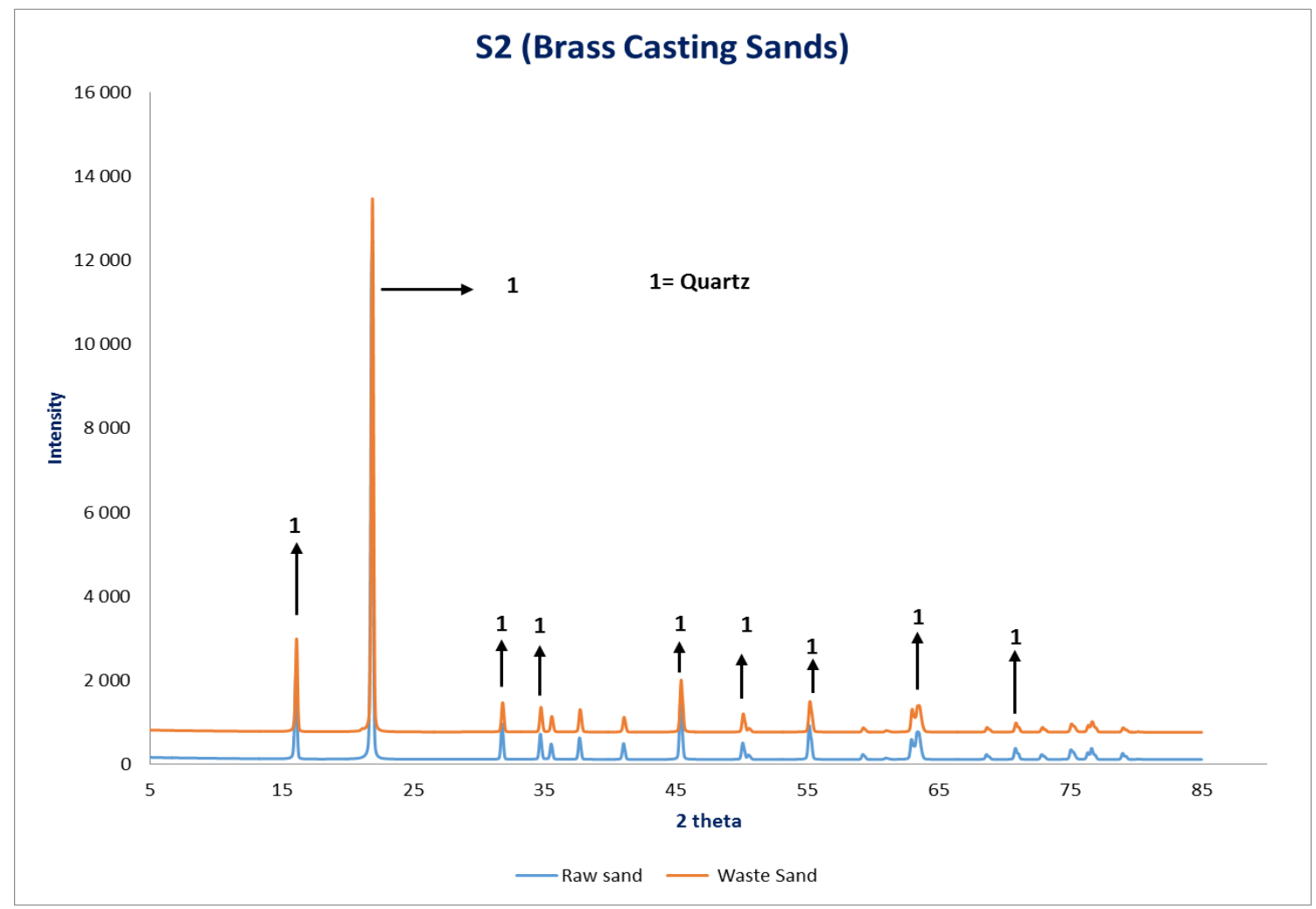


Diffraction pattern 3: Grey Iron casting sand XRD spectrum

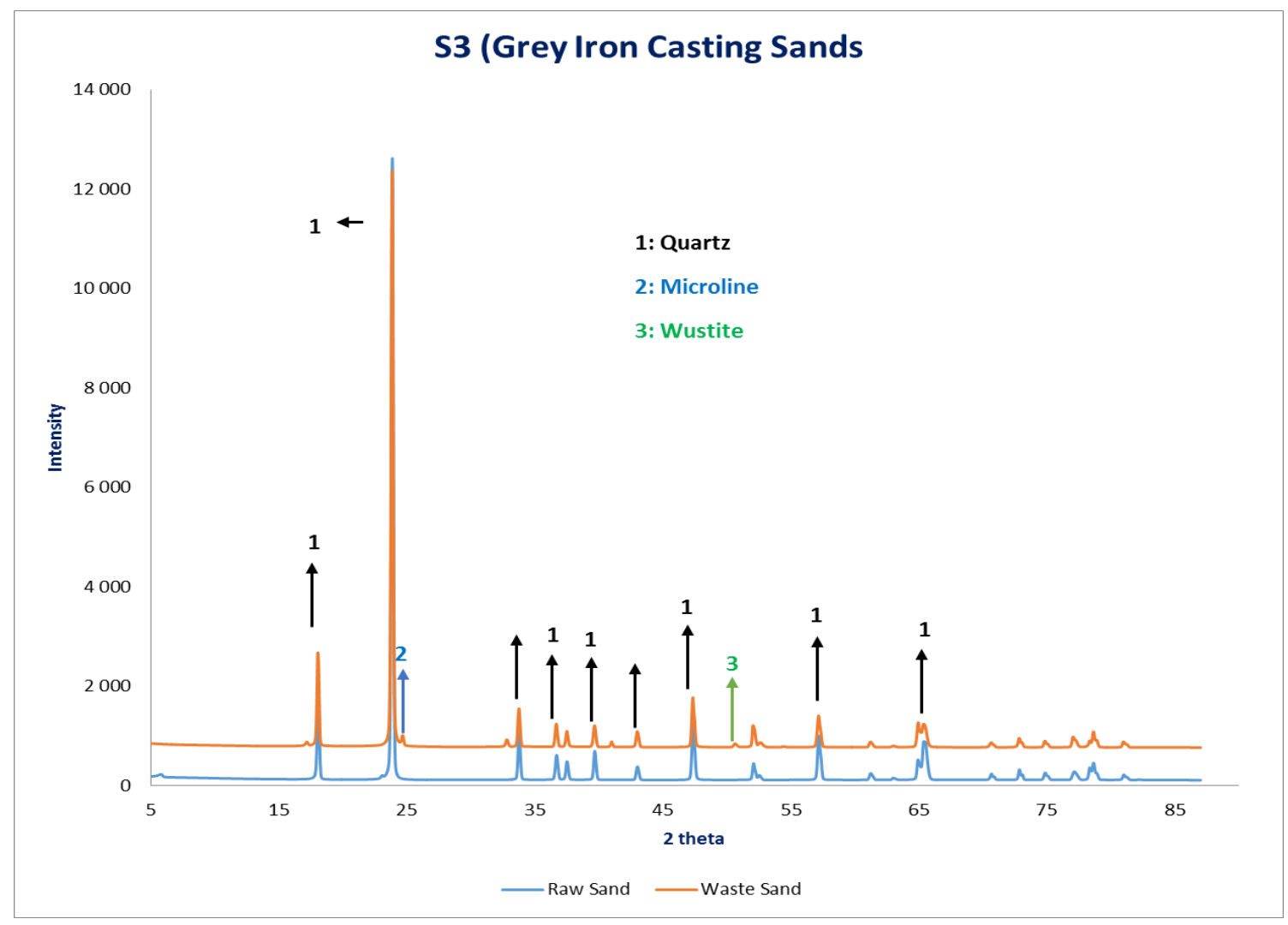

Diffraction pattern 4: High Chrome Casting Sand XRD Spectrum

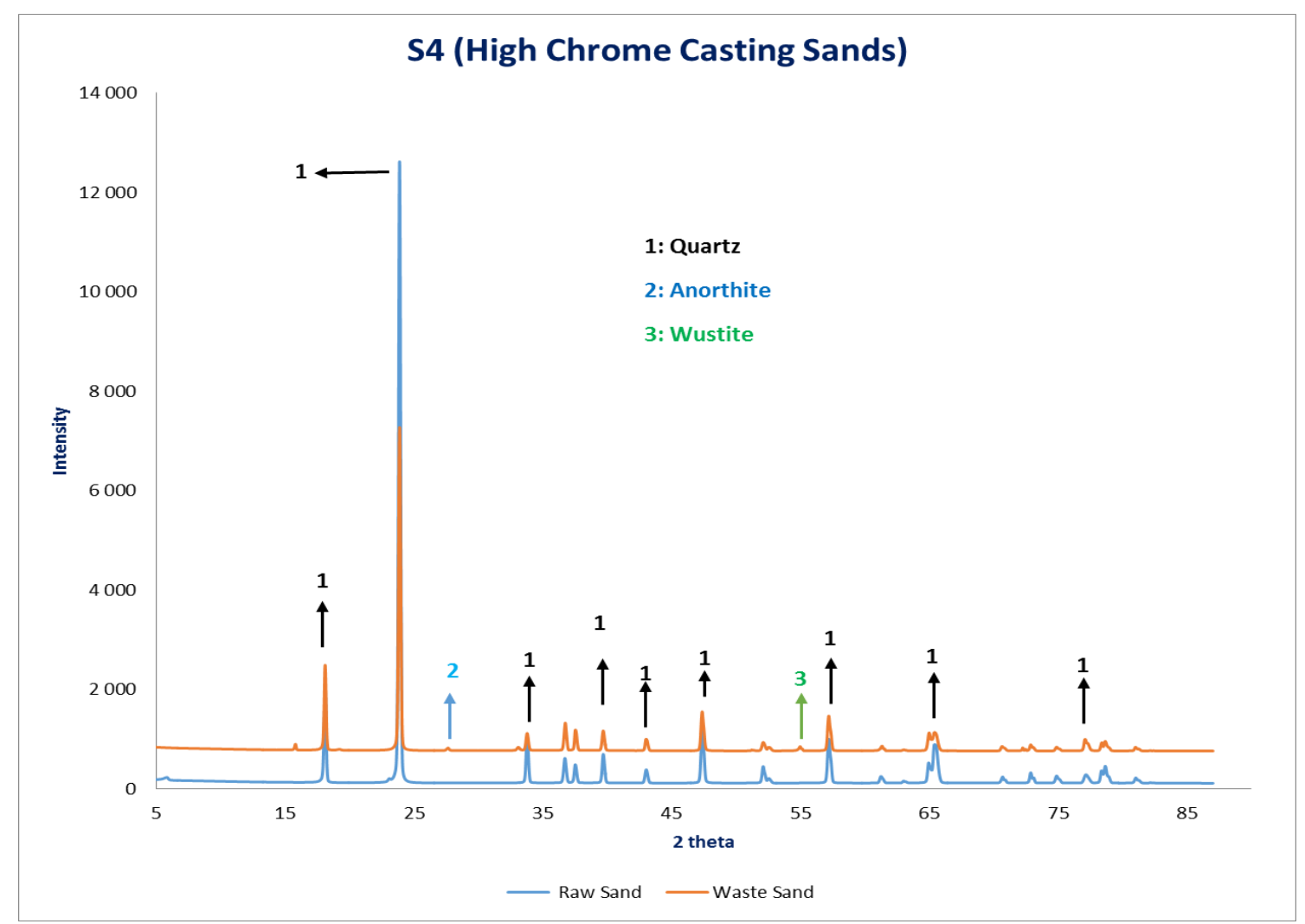


Diffraction pattern 5: Steel Casting Sand XRD Spectrum

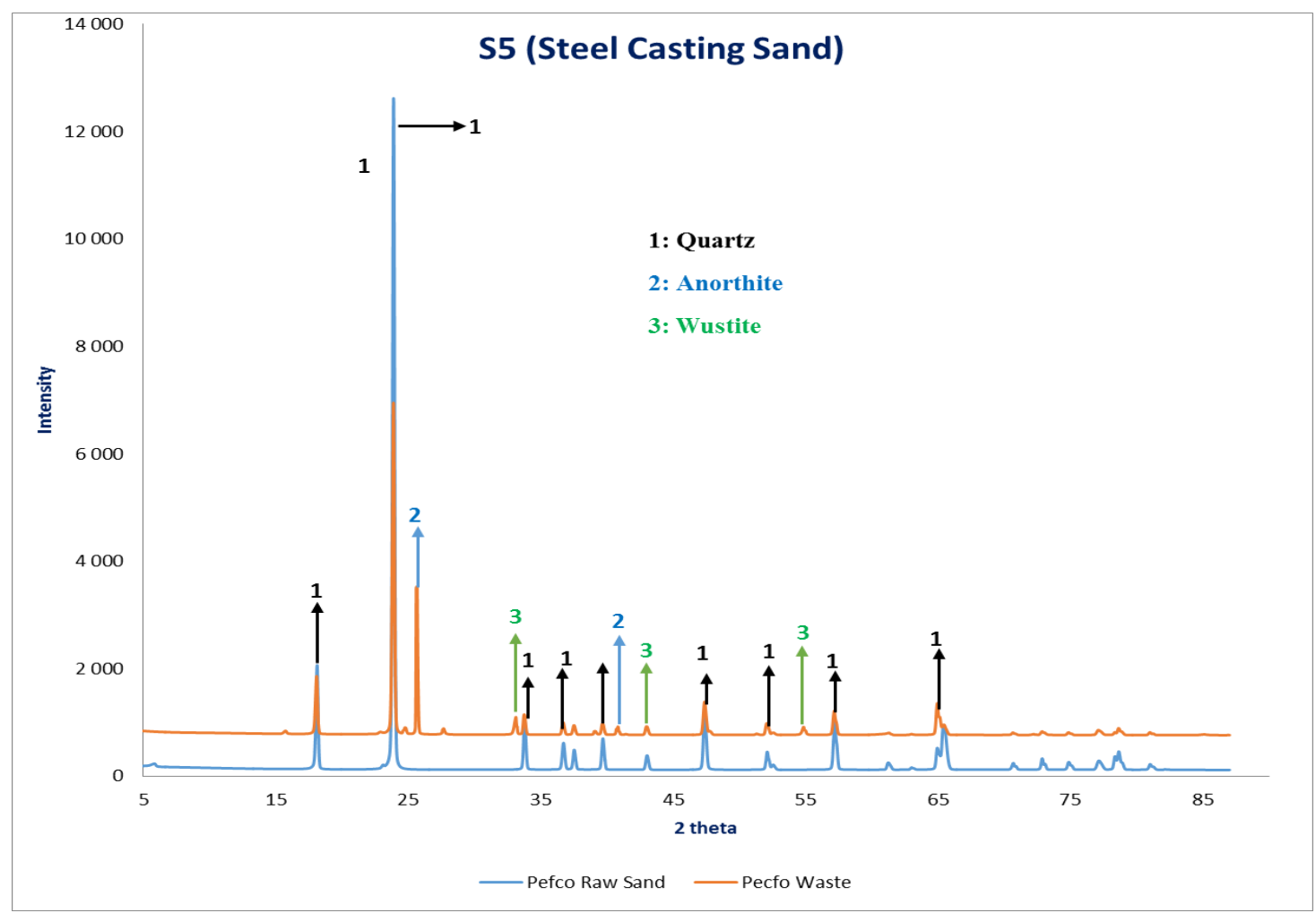

Diffraction pattern 6: Cast Iron casting sand XRD spectrum

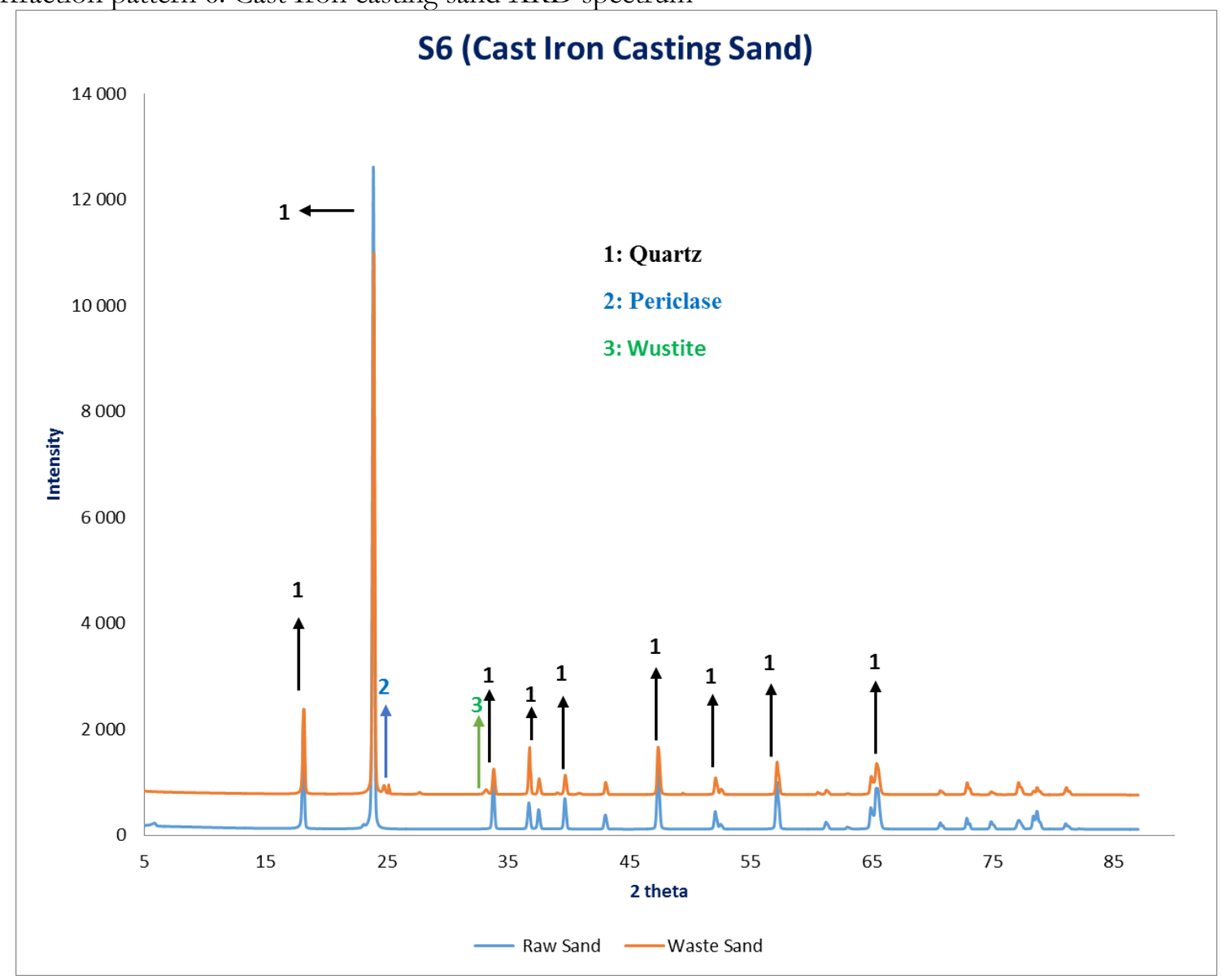


Silica $\left(\mathrm{SiO}_{2}\right)$ was the dominating mineral phase in both sand states (waste and new). However, its peak intensity drastically decreased in high temperature casting alloys, using chemically bonded sand. This was noticed for furan waste sand casting high chrome (diffraction 3) and alkaline phenolic sand for steel (Diffraction pattern 5) and could be attributed to crystallographic metamorphose of $\mathrm{SiO}_{2}$ from trigonal to cubic, which leads to difference intensities of these superstructure reflection [18].

While, in the case of greensand samples casting grey iron (diffraction 3) and cast iron (diffraction 6), the low intensity of the silica peak is associated to the new mineralised phases acting as impurities therefore, lowering the $\mathrm{SiO}_{2}$ peak intensity.

\subsection{Sand Grains Morphological Investigation (SEM-EDS)}

Figures 2 to 7 show the grains morphology of the refractory sands for the diverse casting process, investigated in this study (the new and the waste). It can be witnessed in all the cases that the surface of the virgin (new) sand grain is clean while the waste sand is characterised by a coated grain surface.

The chemical nature of the coating was further discovered by EDS analysis, indicating the presence of residual binder and new phase materials on the waste grain surface.

The pictures below review the SEM results for aluminium casting shell sand:

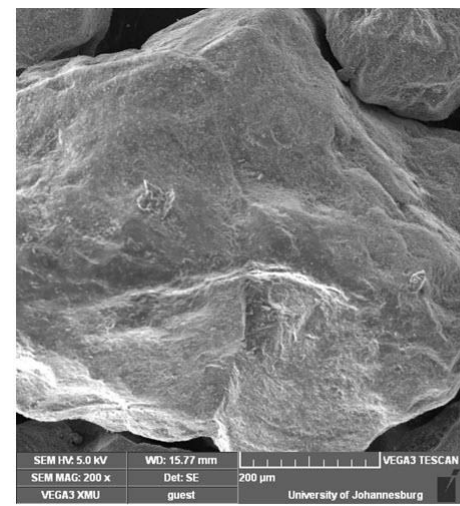

Virgin sand Grain

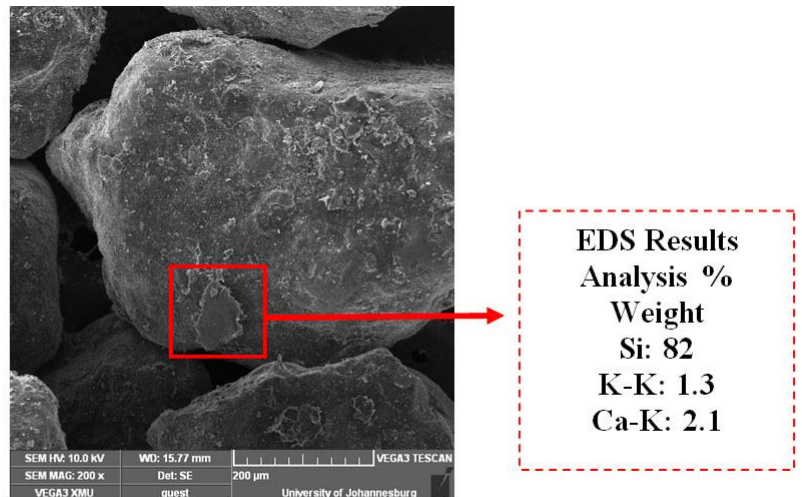

Waste sand Grain

Fig. 2. Aluminium sand grain SEM-EDS result.

The picture bellow summarises the SEM results for brass casting alkyd urethane sand

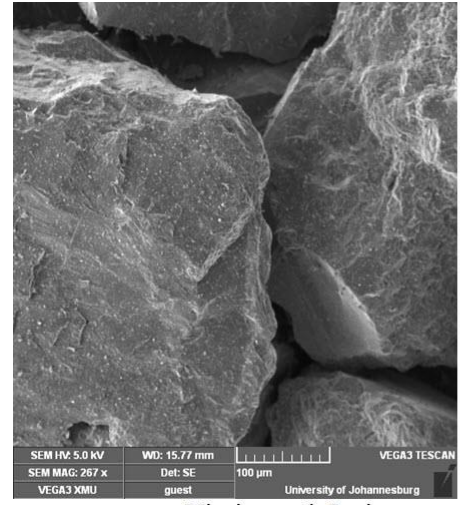

Virgin sand Grain

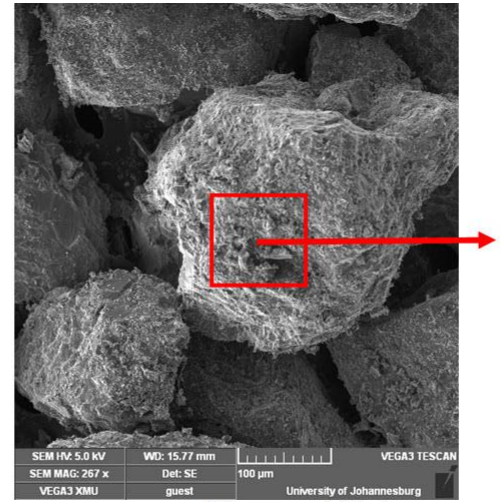

Waste sand Grain

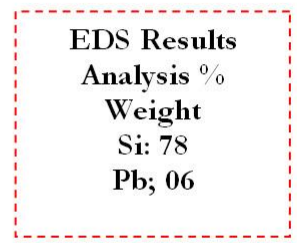

Fig. 3. Brass sand grain SEM-EDS result. 
The picture bellow summarises the SEM results for aluminium casting shell sand:

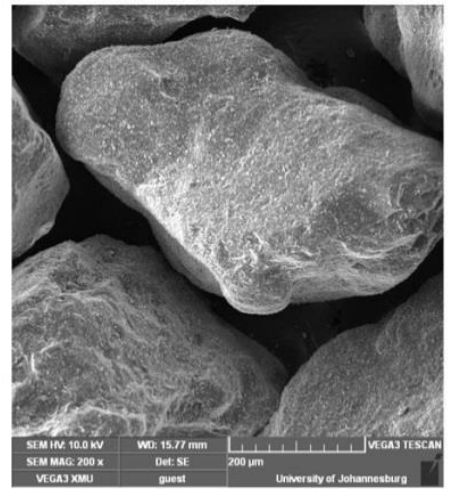

Virgin sand Grain

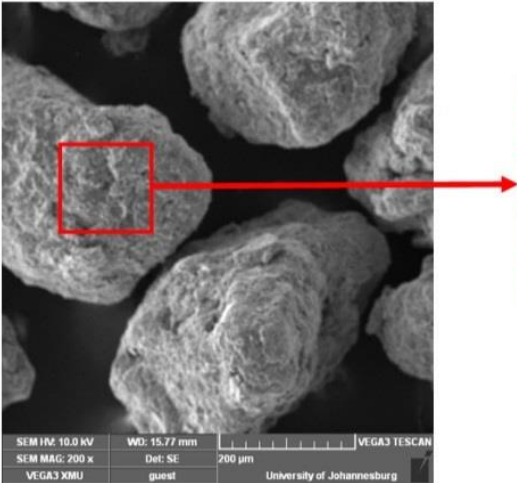

Waste sand Grain
EDS Results

Analysis \%

Weight

Si K: 67

Mg-K: 1.2

Fig. 4. Grey iron casting SEM-EDS result.

The picture bellow summarises the SEM results for high chrome casting furan sand:
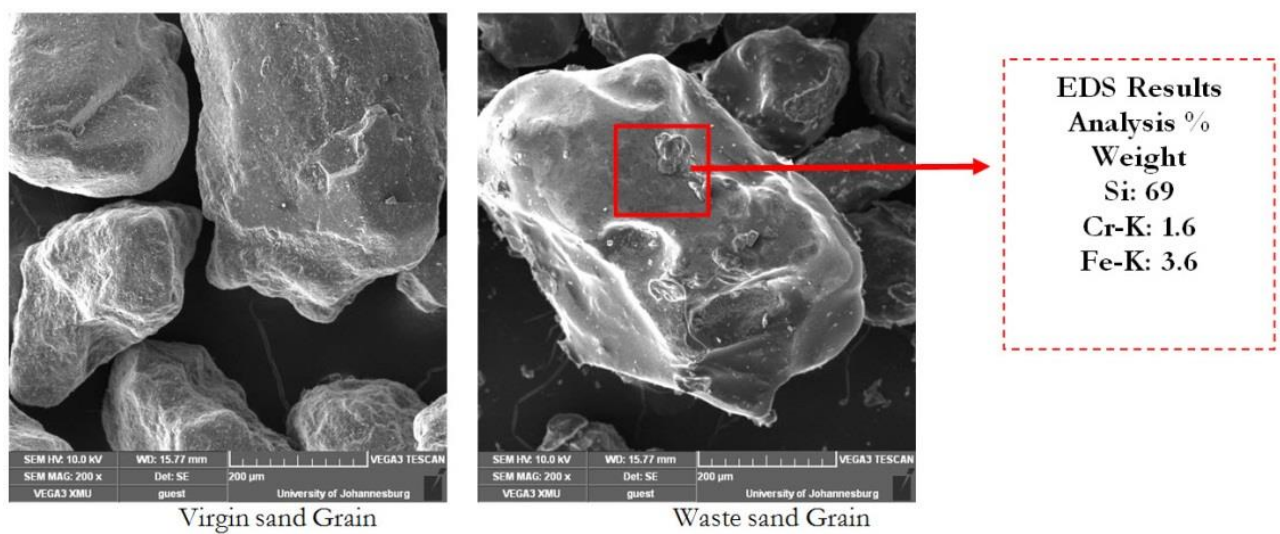

Fig. 5. High chrome sand grain SEM-EDS result.

The picture bellow summarises the SEM results steel casting alkaline phenolic sand:

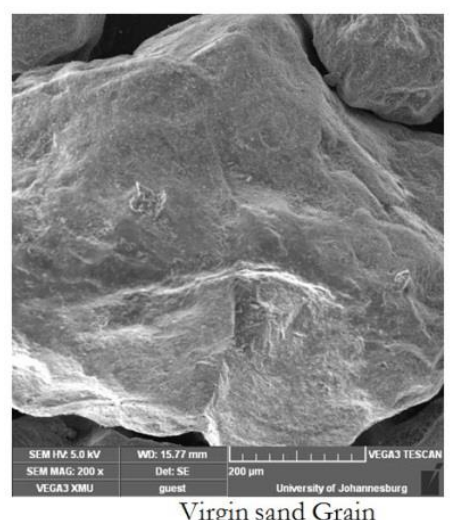

Virgin sand Grain

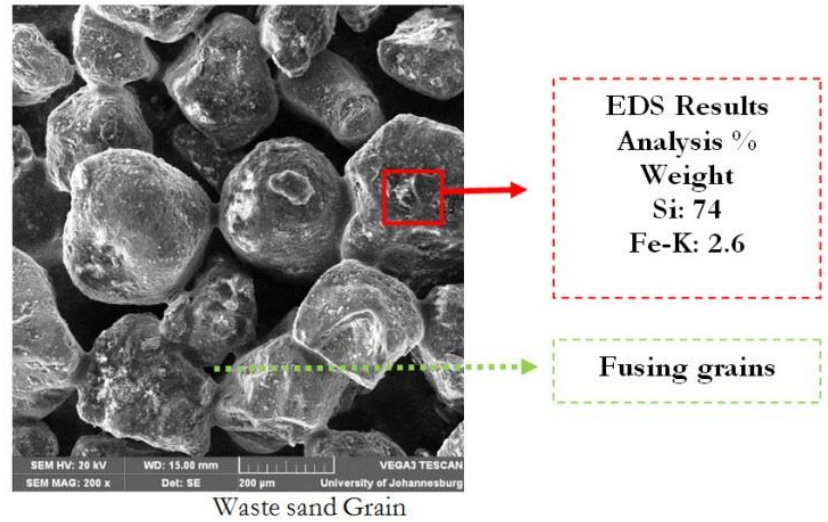

Waste sand Grain

Fig. 6. Steel sand grain SEM-EDS result. 
The picture bellow summarises the SEM results for cast iron greensand sand:

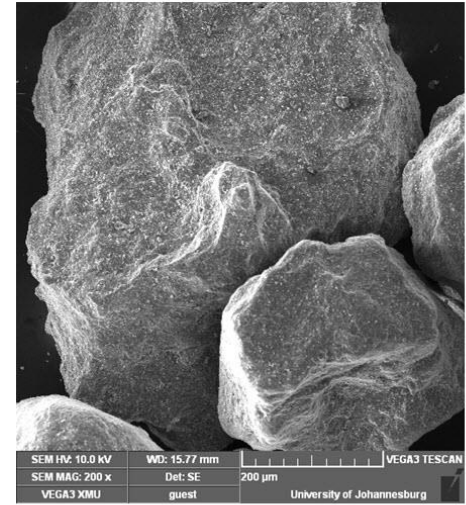

Virgin sand Grain

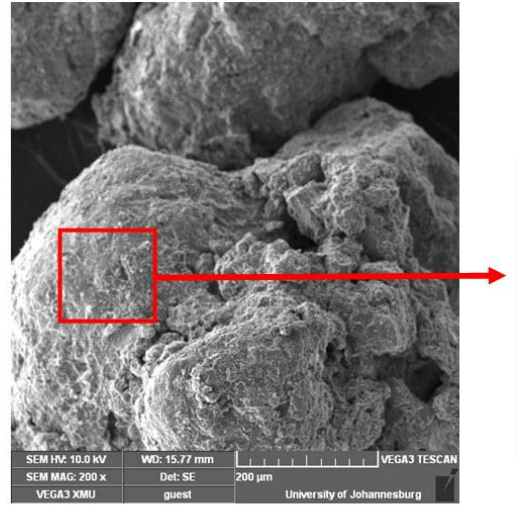

Waste sand Grain

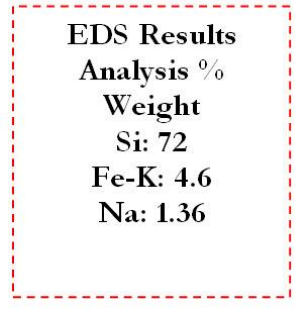

EDS Results

Si: 72

Na: 1.36

Fig. 7. Cast iron sand grain SEM-EDS result.

In the case of aluminium casting in shell moulding (Fig. 2), the EDS of the waste sand indicated the presence of Al-Si material incrusted on the grain sand. This phenomenon is possibly attributed or derived from the main cast alloy ingredient as reported by [19], [20], and [21]. In addition to that, the observed sand grains morphology change, supports the new phase crystalline phase (anorthite) notice under XRD (spectra 1).

Despite the fact that brass casting sand grains did not revealed any crusted material related to the cast alloy as saw in the case of aluminium casting in Fig. 2. The brass waste sand grain clearly indicated the presence of some coating on the refractory sand grain (Fig. 3). The EDS analysis results of the observed coating exposed the presence of $\mathrm{Pb}$. This metal is used in the mould and core paint as metallic drying elements. The observed grain coating is possibly made of dried paint. The presence $\mathrm{Pb}$ support the chemical analysis results obtained under X-ray fluorescence (XRF).

The waste greensand grain obtained independently from the grey iron casting (Figs. 4 and 7) displayed typical oolitic clayey materials coating the sand grain. The EDS results analysis acquired from the oolitilised waste sand grain, revealed the existence of $\mathrm{Na}$ and $\mathrm{Mg}$, indicating the presence of active and dead clayey material. Furthermore, the EDS supported the notice increase of alkalis and alkaline earth element as noticed in the XRF. This was previously mentioned under the study conducted by [22].

The waste sand grain from the high chrome and steel casting (Figs. 5 and 6), presented a glossy coating, revealing fused sand grains. The EDS analysis indicated the presence of Fe. The observed morphology changes supported the decrease in peak intensity as observed in the XRD (diffraction pattern 5 and 6) in terms of crystallographic changes from hexagonal to cubic cause by the high casting temperature.as earlier elaborated in the XRD of these specific sands.

\subsection{Residual Organic Group (FTIR)}

The transition pattern1 summarizes the obtained FTIR spectrum of the tested sands. Similarly, to the preceding conducted characterization technique XRD, the waste sand FTIR spectra, demonstrates that silica remains the main component of the refractory material, as notice at wavenumber $1185 \mathrm{~cm}-1$. This was previously stated by [23]. Nonetheless, the waste sand spectra provide information related to residual organic group and bonds types.

Different transmittance intensities were observed from the tested waste sand samples. The new sands were not subjected to the FTIR analysis. Since, the sand did no go through any mixing (moulding) process. The analysis intended to identify the different organic and functional groups existing in the various waste foundry sand systems (greensand and resin sand), used in this study.

Both waste sand systems (resin and greensand) revealed to possess a relatively similar composition based on their individual spectra shape. It is supported by the presence of silica as the main component of the foundry waste sands. However, the waste resin sand (chemically bonded sand) exhibited higher and wider band peak intensities, compared to the waste greensand samples. The observed peak band differences 
could be explained by the presence residual organic matter and the bond vibration nature exiting in the various sand systems.

Assuming the spectra were baselined resolved, all chemically bonded sands originating from different casting waste sands including the shell sand used in the production of aluminium (S1), the alkyd urethane moulding sands obtained from the brass casting (S2), the furan waste sand from the high chrome casting (S4) and lastly, the waste alkaline phenolic sand used in the production of steel (S5) have shown to have high silica $\left(\mathrm{SiO}_{2}\right)$ band peak located at $1185 \mathrm{cn}-1$ as compared to the both greensand waste (S3 and S6). Suggesting, an intense vibration of the existing Si-O bond, associated to its bending type. While, in the case of waste greensand samples, the low vibration intensity as observed in grey (S3) and cast (S6) iron, associated to the weak Si-O peak, could be attributed to its stretching vibration nature.

Low peak band intensities of aromatic compounds were observed and identified within the region 1500- 1700 in all chemically bonded sand, which could be attributed to the residual existing organic matter contained in the waste resin sand. Since, the identified peak exposed the presence of $C=C$ bond from aromatic alkyl compounds. The latter, were find existent in the greensand waste sand as their spectra were a relatively flat at the same region. Based on the above observation it could be said that the nature of the binder, used for moulding purpose plays a vital role in the chemistry of the sand. In regards, to the organic matter and the bond vibration types as depicted in the transmittance pattern 1 .

\section{Conclusion}

From the conducted study, noticeable changed were observed within the waste foundry sand when compared to its corresponding virgin (new) sand samples. The chemical analysis under XRF has shown silica as the primary constituent of the waste sand. However, metallic traces associated to the cast alloy were found in high proportion in the waste than in the raw (new) sand. Furthermore, new mineral phases, inexistent in the virgin sand, were found in the waste sand depending on the cast alloy and the binder type. In addition, morphology differences were observed from both grains types: new and waste. The latter, grains were coated by thin layers of residual binders. Lastly, the waste and raw sand receded the same spectra under the FTIR. Nonetheless different band peak intensity was notice and attributed to the binder used.

\section{Acknowledgements}

The authors are thankful to the Metallurgy Department at the University of Johannesburg, to the local foundries who participate in the research work, to the metal casting technology station (UJ-MCTS) and South African Institute of Foundry men (SAIF). 


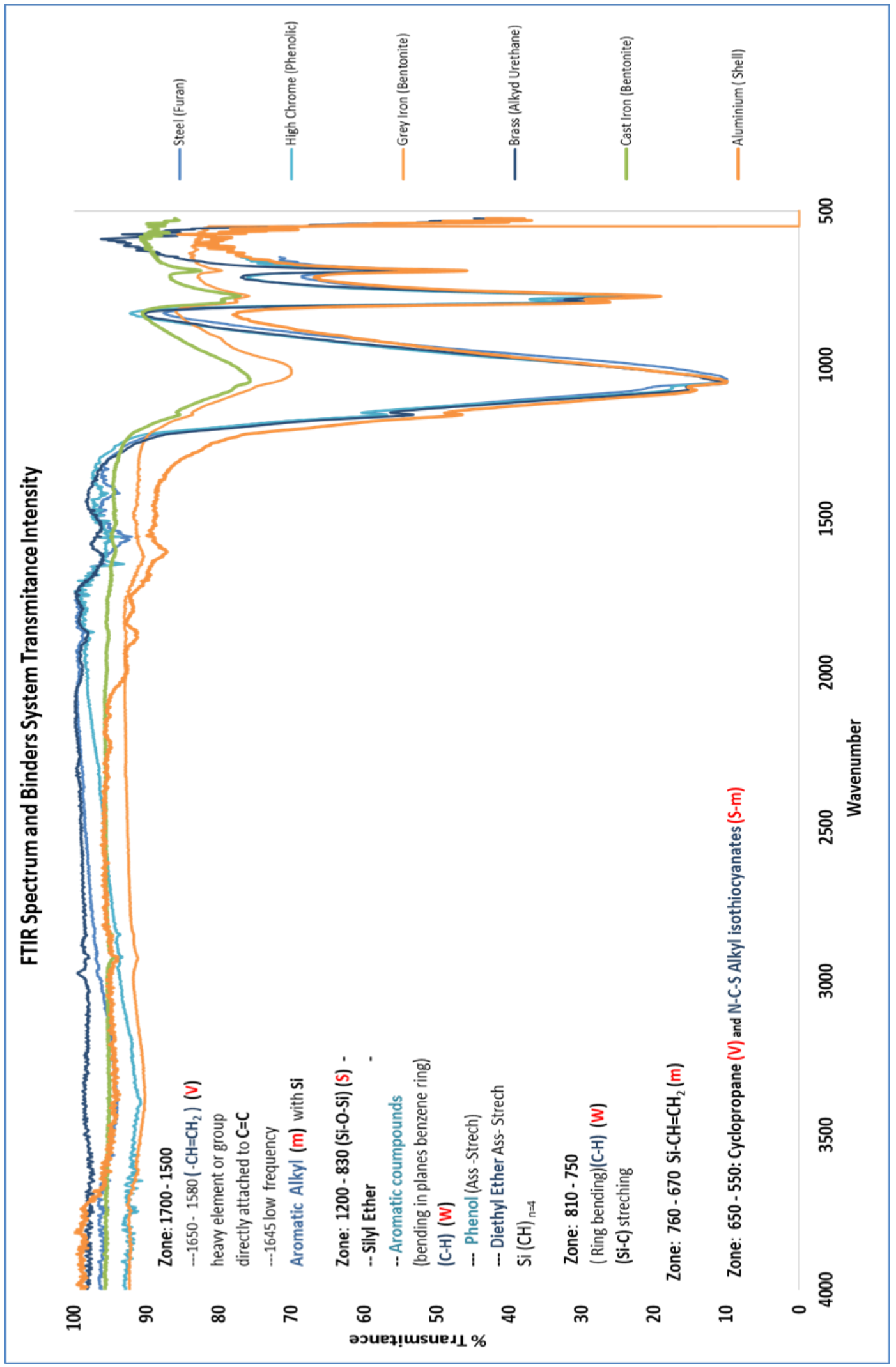

\section{References}

[1] V. Jaiganesh and K. Prakasan, "Hydraulics, dimensional analysis and visualization of flow through unpressurized gating systems using water models," Engineering Journal, vol. 20, no. 1, pp. 168-185, Jan. 2016. 
[2] J. K. Nyembwe, M. E. Makhatha, T. Madzivhandila, and K. D. Nyembwe, "Characterisation of South African waste foundry moulding sand: Metallic contaminants," in Proceedings of the World Congress on Mechanical, Chemical and Material Engineering (MCM 2015) Barcelona, Spain, July 20 - 21, 2015, Paper No. 362.

[3] A.E. Mohamadi, South Africa Foundry Market. Beijing: NFTN, 2012, p. 6.

[4] A.E. Mohamadi, A Collective Approach Towards Green Foundries In South Africa. Johannesburg: NFTN, 2012.

[5] A. Deng, "Excess foundry sand characterization and experimental investigation in controlled lowstrength material," Ph.D. dissertation, Pennsylvania State University, 2004.

[6] S. Firat, G. Yilmaz, A. T. Cömert, and M. Sümer, "Utilization of marble dust, fly ash and waste sand (silt-quartz) in road subbase filling materials," Journal of Civil Engineering, vol. 16, no. 7, pp. 1143-1151, Sept. 2012.

[7] R. A. Mustafa, H. A. Abdul, S. Mohamed, and F. A. Bakar, "Total phenolic compounds, flavonoids, and radical scavenging activity of 21 selected tropical plants," Journal of Food Science, vol. 75, no. 1, pp. C28-C35, 2010.

[8] M. A. Mastella, E. S. Gislon, F. Pelisser, C. Ricken, L. da Silva, E. Angioletto, and O. R. K. Montedo, "Mechanical and toxicological evaluation of concrete artefacts containing waste foundry sand," Waste Management, vol. 34, no. 8, pp. 1495-1500, 2014.

[9] K. B. Rundman, "Metal casting," Department of Materials Science and Engineering, Michigan Technology University, MY4130, 2000.

[10] B. C. Smith, Infrared Spectral Interpretation: A Systematic Approach. CRC Press, 1999, ch. 7, pp. 165-174.

[11] S. Costley, "Waste classification and management regulations and supporting norms and standards," Hazardous Waste Management, Departement of Enviromental Affairs, South Africa, 2013.

[12] H. Benson and S. Bradshaw, User Guideline for Foundry Sand In Green Infrastructure. Madison, WI, USA, 2014.

[13] H. Zhang, L. Su, X. Li, J. Zuo, G. Liu, and Y. Wang, "Evaluation of soil microbial toxicity of waste foundry sand for soil-related reuse," Frontiers of Environmental Science and Engineering, vol. 8, no. 1, pp. 89-98, Oct. 2013.

[14] K. Simmons, "Soil sampling," US Environmental Protective Agency (US-EPA), Georgia, USA, Aug. 2014.

[15] B. S. Alves, R. S. Dungan, R. L. Carnin, R. Galvez, and C. R. de Carvalho Pinto, "Metals in waste foundry sands and an evaluation of their leaching and transport to groundwater," Water, Air, and Soil Pollution, vol. 225, no. 5, pp. 1-11, 2014.

[16] M. Şahmaran,, M. Lachemi,, T. K. Erdem, and H. E. Yücel,, "Use of spent foundry sand and fly ash for the development of green self-consolidating concrete," Materials and Structures, vol. 44, no. 7, pp. 1193-1204, Nov. 2010.

[17] B. J. Maynard, M. David, and P. Kwan. "Kinetics of lead release from brass water meters and faucets," in WQTC Conference Proceedings, American Water Works Association, Cincinnati, OH, 2008.

[18] A. I. Gusev, A. A. Rempel, and A. L. Magerl, "Disorder and order in strongly nonstoichiometric compound," in Transition Metal Carbides, Nitrides and Oxides. Springer, 2001.

[19] G. Penkaitis and J. B. Sígolo, "Waste foundry sand: Environmental implication and characterization," Revista do Instituto de Geociências -USP, vol. 12, no. 3, pp. 5-70, Dec. 2012

[20] W. C. Fourie, GHS Classification Of Company A Spent Foundry Sand And Assessment For Landfill Disposal. South Africa: Infotox and CSIR, 2011.

[21] Y. Guney, A. H. Aydilek, and M. Demirkan, "Geoenvironmental behavior of foundry sand amended mixtures for highway subbases," Waste Management, vol. 26, no. 9, pp. 932-945, Jun. 2005.

[22] J. C. D. de Oliveira and A. A. B Pecora, "Experimental study of thermal regeneration of foundry sand in a fluidized bed incinerator," in Proc. 18th International Congress of Mechanical Engineering, Nov. 6-11, 2005, ABCM, Ouro Preto, MG.

[23] M. de Miguel, J. A. Cabezas, N. de María, D. Sánchez-Gómez, M. Á. Guevara, M. D. Vélez, E. SáezLaguna, L. M. Díaz, J. A. Mancha, M. C. Barbero, and C. Collada, "Genetic control of functional traits related to photosynthesis and water use efficiency in Pinus pinaster Ait. drought response: integration of genome annotation, allele association and QTL detection for candidate gene identification," BMC Genomics, vol. 15, no. 1, p. 1, 2014. 